\title{
Antidiabetic Activity of Pterospermum acerifolium Flowers and Glucose Uptake Potential of Bioactive Fraction in L6 Muscle Cell Lines with Its HPLC Fingerprint
}

\author{
Rathinavelusamy Paramaguru, Papiya Mitra Mazumder, \\ Dinakar Sasmal, and Venkatesan Jayaprakash \\ Department of Pharmaceutical Sciences, Birla Institute of Technology, Mesra, Ranchi, Jharkhand-835215, India \\ Correspondence should be addressed to Papiya Mitra Mazumder; pmitramazumder@bitmesra.ac.in
}

Received 21 February 2014; Revised 12 August 2014; Accepted 19 August 2014; Published 21 October 2014

Academic Editor: Giuseppe Valacchi

Copyright (C) 2014 Rathinavelusamy Paramaguru et al. This is an open access article distributed under the Creative Commons Attribution License, which permits unrestricted use, distribution, and reproduction in any medium, provided the original work is properly cited.

\begin{abstract}
The present study was designed to estimate the detailed antidiabetic activity of Pterospermum acerifolium (L.) Willd flowers. In vitro alpha amylase inhibition study was carried out on $50 \%$ ethanol extract of flowers (PAFEE) and its various fractions. The active ethyl acetate fraction (PAFEF) was subfractionated into three subfractions (PAFE1, PAFE2, and PAFE3) and subjected to acute toxicity studies followed by antidiabetic screening in vivo by streptozotocin-nicotinamide induced type II diabetes. Diabetic animals treated with PAFE2 $(30 \mathrm{mg} / \mathrm{kg})$ reduced the levels of fasting blood glucose, significantly $(P<0.001)$ compared to that of diabetic control animals. Histological studies on drug treated groups did not show remarkable positive changes in $\beta$-cells. PAFE2 showed $32.6 \pm 1.93 \%$ glucose uptake over control and, in the presence of PI3K inhibitor wortmannin, declined to $13.7 \pm 2.51 \%$. HPLC analysis of PAFE2 reveals the presence of quercetin and apigenin as major constituents and both are inhibiting the glycogen phosphorylase enzyme in molecular modelling studies. The study evidenced strongly that the probable glucose lowering mechanism of action of active subfraction PAFE2 is by increasing the glucose uptake in peripheral tissues and by inhibition of gluconeogenesis.
\end{abstract}

\section{Introduction}

Diabetes mellitus is the most common endocrine disorder resulting from insulin deficiency which in turn leads to chronic hyperglycemia with disturbances of carbohydrate, fat, and protein metabolism [1]. It is majorly classified into insulin dependent diabetes mellitus (Type I) and noninsulin dependent diabetes mellitus (Type II); type II diabetes mellitus is the most common endocrine disorder worldwide, covering about $90-95 \%$ of all diabetes cases [2]. The classification and pathogenesis of type II diabetes involves abnormalities in glucose and lipid metabolism, inadequate insulin secretion from pancreatic beta-cells, and resistance to insulin activity [3]. The prevalence of type 2 diabetes continues to increase at an alarming rate globally. Even though the pathogenesis and long term complications of type 2 diabetes are fairly well known, its treatment has remained challenging [4].
Currently available therapeutic measurements to treat type II diabetes mellitus also have certain adverse effects like causing hypoglycemia at higher doses, liver problems, lactic acidosis, and diarrhea [5].

Pterospermum acerifolium (L.) Willd (Sterculiaceae) is commonly known as Kanakchampa, traditionally used for hemostasis, inflammation, ear pain, stomach-ache, blood troubles, small pox, leucorrhoea, leprosy, ulcer, and tumours and as antihyperglycemic agent, laxative, and anthelmintic [6,7]. The flowers of Pterospermum acerifolium are commonly consumed by the tribal folks of Chota Nagpur region of Jharkhand, India. The phytoconstituents reported from flower were $24 \beta$-ethylcholest-5-en-3-beta-0alpha-cellobiside, 3,7-diethyl-7-methyl-1:5-pentacosanolide, $\mathrm{n}$-hexacosane-1,26-dioldilignocerate, friedelan- $3 \alpha$-ol, and its $\beta$-isomer, $\beta$-amyrin, $\beta$-sitosterol, $\mathrm{n}$-triacontanol, $\mathrm{n}$-hexacosane-1,26-diol, myristic, palmitic, stearic, arachidic, behenic, 
lignoceric, oleic, linoleic, linolenic acids, kaempferol, $4^{\prime}$ methoxy-kaempferol, and kaempferide-7-O- $\beta$-D-glucopyranoside [8]. Literature survey of plant showed that these plant extracts are showing antidiabetic properties but knowledge is very imprecise. The studies if at all are limited to extract level only and moreover detailed parameters, which could be claimed as well defined hypoglycemic activity of the plant is lacking. In order to explore the full potential of this plant as useful antidiabetic agent, it is necessary to carryout systemic studies of these plants and extracts responsible for antidiabetic activity. Hence this work is designed for evaluation of the antidiabetic property on the basis of bioactivity guided fractionation, estimation of mechanism of action of bioactive subfraction by which it controls the blood glucose level, and identification of bioactive constituents present in the active subfraction by HPLC analysis.

\section{Materials and Methods}

2.1. Plant Material. Flowers of Pterospermum acerifolium collected from the campus of BIT Mesra, Ranchi in the month of March 2011. The plant material had been identified and authenticated from Dr. Karthikeyan, taxonomy department of Botanical survey of India (BSI), Kolkata. The voucher specimen (CNH/48/2012/Tech II/805) was retained in the Department of Pharmaceutical Sciences, BIT Mesra, Ranchi for future reference.

2.2. Extraction and Fractionation. The shade dried flowers were powdered $(1 \mathrm{~kg})$ and extracted with $50 \%$ ethanol for the period of $72 \mathrm{~h}$ and subsequently concentrated to obtain a yield of $61.32 \mathrm{~g}$ of $50 \%$ ethanol extract of flower (PAFEE). Twentyfive grams of the extract was dissolved in distilled water and extracted successively with hexane (PAFHF), chloroform (PAFCF), and ethyl acetate (PAFEF) and concentrated to dryness to obtain the respective fractions.

2.3. $\alpha$-Amylase Inhibition Assay. A modified form of SigmaAldrich method was used [9]. The $\alpha$-amylase inhibition was expressed as percent of inhibition and it was calculated as $100-\%$ reaction where by the $\%$ reaction $=$ (maltose in test/maltose in control) $\times 100$.

2.4. Subfractionation of Ethyl Acetate Fraction. The ethyl acetate fraction was subfractionated by column chromatography. Crude fractions were adsorbed in silica gel (mesh 60-120) for uniform mixing. Using dichloromethane as solvent, the column was packed with silicagel (mesh 100200). The column was eluted with dichloromethane followed by methanol, dichloromethane in the regular increased proportion of methanol. Each fraction was tested in TLC plate for its homogeneity and pulled together into three fractions and evaporated under room temperature to yield the subfractions PAFE1, PAFE2, and PAFE3.

2.5. Animals. Healthy male albino rats (Wistar strain 180$200 \mathrm{~g}$ ) were procured from the animal house of Birla Institute of Technology. They were housed in clean polypropylene cages with free access to standard laboratory pellet diet and water at room temperature $27 \pm 2^{\circ} \mathrm{C}$ with an inverted $12: 12 \mathrm{~h}$ light-dark cycle and relative humidity of $60 \%$. The animals were acclimatized for 7 days before the commencement of the experiments. The experimental protocols were approved by the Institutional Animal Ethics Committee (BIT/PH/IAEC/34/2011).

2.6. Acute Oral Toxicity Studies and Dose Fixation. Toxicity studies conducted on female mice based on OECD guidelines 423 for acute oral toxicity-acute toxic class method. For ethyl acetate fraction (PAFEF) $2000 \mathrm{mg} / \mathrm{kg}$ was fixed as initial dose and for subfractions (PAFE1, PAFE2, and PAFE3) $300 \mathrm{mg} / \mathrm{kg}$ was fixed as initial dose and the test substance was administered in a single dose by using an intragastric tube. Animals were observed individually after dosing at least once during the first 30 minutes, periodically during the first 24 hours, with special attention given during the first $4 \mathrm{~h}$, and daily thereafter, for a total of 14 days.

2.7. Induction of Diabetes. Streptozotocin (STZ) was dissolved in citrate buffer ( $\mathrm{pH} 4.5$ ) and nicotinamide was dissolved in normal physiological saline. Noninsulin dependent diabetes mellitus was induced in overnight fasted rats by a single intraperitoneal injection of STZ $(60 \mathrm{mg} / \mathrm{kg}$ b.w.). 15 min later, the rats were given the intraperitoneal administration of nicotinamide ( $120 \mathrm{mg} / \mathrm{kg}$ b.w.). Hyperglycemia was confirmed by the elevated glucose levels, determined at $72 \mathrm{~h}$. The animals with blood glucose concentration more than $250 \mathrm{mg} / \mathrm{dL}$ were included in the study [10].

2.8. Experimental Design. Animals were divided into 11 groups and each group consisted of 6 animals.

Group I: normal control (2\% tween $80 ; 1 \mathrm{~mL} / \mathrm{kg}$ b.w.). Group II: diabetic control rats receiving sterile water. Group III: PAFEF1; diabetic animals treated with PAFEF $200 \mathrm{mg} / \mathrm{kg}$ b.w.

Group IV: PAFEF2; diabetic animals treated with PAFEF $400 \mathrm{mg} / \mathrm{kg}$ b.w.

Group V: PAFE1-1; diabetic animals treated with PAFE1 $15 \mathrm{mg} / \mathrm{kg}$ b.w.

Group VI: PAFE1-2; diabetic animals treated with PAFE1 $30 \mathrm{mg} / \mathrm{kg}$ b.w.

Group VII: PAFE2-1; diabetic animals treated with PAFE2 $15 \mathrm{mg} / \mathrm{kg}$ b.w.

Group VIII: PAFE2-2; diabetic animals treated with PAFE2 $30 \mathrm{mg} / \mathrm{kg}$ b.w.

Group IX: PAFE3-1; diabetic animals treated with PAFE3 $15 \mathrm{mg} / \mathrm{kg}$ b.w.

Group X: PAFE3-2; diabetic animals treated with PAFE3 $30 \mathrm{mg} / \mathrm{kg}$ b.w.

Group XI: STD drug; diabetic animals treated with $600 \mu \mathrm{g} / \mathrm{kg}$ b.w. of glibenclamide.

Plant extracts, glibenclamide and vehicle, were administered via the intragastric tube for 30 days. 
2.9. Biochemical Analysis. Oral glucose tolerance test (OGTT) was performed in overnight fasted normal and drug treated rats on 15th day of treatment [11]. The fasting blood glucose was measured on day $0,14,21$, and 28 by using glucometer (Bayer's blood glucose measuring kit with counter strips). On the 30th day, blood was collected in the EDTA coated tubes for measuring glycosylated hemoglobin $\left(\mathrm{HbA} 1_{\mathrm{C}}\right.$ ) by using commercial kit (coral $\mathrm{HbA} 1_{\mathrm{C}}$ estimation kit) and blood was collected in tubes without anticoagulant for serum preparations. Serum was analyzed for ALT (Alkaline transaminase), AST (Aspartate transaminase), ALP (Alkaline phosphatase) by cogent Serum-ALT, AST, ALP Estimation Kits (Span diagnostics limited). Triglycerides, Total cholesterol (TC), HDL-C was estimated by Autospan triglycerides, TC, HDL-C estimation kits (Span diagnostics limited). Further TBARS [12], catalase [13], superoxide dismutase [14], and reduced glutathione [15] were estimated from liver homogenate.

2.10. Histopathology of Pancreas. The pancreas from normal control, diabetic control, and maximum drug dose treated animals were blotted free of mucus. The tissues were washed in normal saline, cut into desired size, and fixed in $10 \%$ formalin for $24 \mathrm{~h}$. After fixation, tissues were cleaned and embedded in paraffin. Sections of tissue were made in rotary microtome of $5 \mu \mathrm{m}$ in thickness and mounted on slides. The mounted slides were stained with haematoxylin and eosin for photographic observations.

2.11. Glucose Uptake Study on L6 Muscle Cell Lines in the Presence and Absence of Wortmannin. The determination of cell viability was performed by MTT assay [16]. Twenty four hour cell cultures with $70-80 \%$ confluency in $40 \mathrm{~mm}$ petri plates were allowed to differentiate by maintaining in DMEM with $2 \%$ FBS for 4-6 days. The differentiated cells were used to measure the cell-associated glucose using glucose assay kit (Biovision Inc., USA) [17]. For PI3-K inhibition studies, L6 myotubes were treated with wortmannin $100 \mathrm{nM}, 30 \mathrm{~min}$ prior to the incubation with the PAFE2 $(1000 \mu \mathrm{g} / \mathrm{mL})$ and standard Insulin $(1 \mathrm{IU} / \mathrm{mL})$ followed by the glucose uptake assay [18].

2.12. HPLC Analysis. The active subfraction was subjected to analysis by being dissolved in HPLC grade methanol $(1 \mathrm{mg} / \mathrm{mL})$. The HPLC system (Waters 510, Japan) was equipped with dual pump binary system, $\mathrm{C}_{18}$ reversed-phase column, GL Sciences Inc., Japan (I.D. $4.6 \mathrm{~mm} \times 250 \mathrm{~mm}$, $5 \mu \mathrm{m})$. Flow rate and injection volume were $1.0 \mathrm{~mL} / \mathrm{minute}$ and $20 \mu \mathrm{L}$, respectively. The samples were monitored with UV detection at $320 \mathrm{~nm}$ at room temperature. Separation was achieved with a two-pump linear gradient program for pump A (water containing $0.1 \%$ formic acid) and pump B (acetonitrile). Elution was started with a gradient of $10 \% \mathrm{~B}$ changing to $70 \%$ in 25 minutes and finally to $10 \%$ in 35 minutes followed by washing for 40 minutes. The chromatographic peaks of the analytes were confirmed by comparing their retention time and UV spectra with corresponding reference standards. The reference standards used were gallic acid, chlorogenic acid, rutin, quercetin, apigenin, and kaempferol.
2.13. Molecular Docking Studies. Quercetin and apigenin were identified as the major components present in bioactive subfraction. Hence both were selected as a ligand for molecular docking studies as remaining compounds were not of any therapeutic significance.

The autodock 4.2 docking software was used to perform molecular docking simulation between rabbit muscle glycogen phosphorylase and quercetin, apigenin. The crystal structure of glycogen phosphorylase complexed with acyl urea derivatives (PDB CODE: $1 \mathrm{WV1}$ ) at $2.26 \AA$ resolution was downloaded from the RCSB Protein Data Bank (http://www.rcsb.org/pdb/home/home.do). MGLTools-1.4.6 was used to prepare protein (protein.pdbqt) and to write grid parameter file (protein.gpf) and docking parameter file (ligand.dpf). Protein preparation includes (i) removal of water and ions and extraction of cocrystallized ligand; (ii) addition of polar hydrogens; (iii) assignment of AD4 atom type; and finally (iv) assignment of Gasteiger charges. The grid maps representing the native ligand in the actual docking target site were calculated with autogrid 4 with box dimension of $60 \times 60 \times 60 \AA$ and spacing of $0.375 \AA$ by taking centre of the ligand as centre of the grid. Docking of ligand was done with default parameters except keeping 50 runs.

2.14. Statistical Analysis. The results are expressed as mean \pm standard error of the mean (SEM). Statistical analysis of all the data were evaluated according to one-way analysis of variance (ANOVA) using statistical software Graphpad prism version 6 . The significance of difference was evaluated using one-way ANOVA followed by Dunnett's multiple comparison test. Probability values of aaaa $P<0.0001$, ${ }^{\text {aaa }} P<0.001$, ${ }^{\text {aa }} P<0.01,{ }^{\text {a }} P<0.05$ were compared with normal control. Probability values of ${ }^{\text {bbbb }} P<0.0001,{ }^{\text {bbb }} P<0.001,{ }^{\text {bb }} P<$ $0.01,{ }^{\mathrm{b}} P<0.05$ were compared with disease control.

\section{Results}

3.1. In Vitro $\alpha$-Amylase Inhibition Study. The results of $\alpha$ amylase inhibition study revealed that ethyl acetate fraction (PAFEF) possess higher enzyme inhibition potential (73.70\%) compared to all other fractions followed by $50 \%$ ethanolic extract (PAFEE) which showed noticeable enzyme inhibition potential (47.44\%); next to that, chloroform fraction showed $21.24 \%$ inhibition potential and n-hexane fraction did not show positive inhibition potential. Hence for further studies ethyl acetate fraction (PAFEF) was selected.

3.2. Acute oral Toxicity. Acute oral toxicity studies revealed the nontoxic nature of flowers of $P$. acerifolium at the dose levels tested. No lethality or toxic reactions were observed until the end of the study. Mortality was not recorded during 14 days on drug treated animals. Hence the doses were fixed as $200 \mathrm{mg} / \mathrm{kg}$ and $400 \mathrm{mg} / \mathrm{kg}$ for PAFEF and $15 \mathrm{mg} / \mathrm{kg}$ and $30 \mathrm{mg} / \mathrm{kg}$ for subfractions (PAFE1, PAFE2, and PAFE3).

3.3. Effect of $P$. acerifolium on OGTT. In oral glucose tolerance test, the blood glucose levels of glucose loaded experimental animals were increased markedly at $30 \mathrm{~min}$. 
PAFE2-2 $(30 \mathrm{mg} / \mathrm{kg})$ inhibited the increasing blood sugar level significantly $(P<0.01)$ in the 60th min and the 120 th min when compared with the diabetic control. None of the other fractions controlled the blood glucose significantly when compared with the diabetic control (Table 1).

3.4. Effect of P. acerifolium on Fasting Blood Glucose Levels, Body Weight, and $\mathrm{HbA1}_{\mathrm{C}}$. In flowers, fasting blood glucose levels were increased significantly $(P<0.0001)$ compared with the normal control in all the observed days. On day 14 , when compared to diabetic control, PAFE2-2 $(30 \mathrm{mg} / \mathrm{kg})$ reduced the blood glucose level significantly $(P<0.01)$ in diabetic animals. On day 21 , when compared to diabetic control, PAFE2-2 (30 mg/kg) reduced the blood glucose level significantly $(P<0.001)$, and PAFE1-1 $(15 \mathrm{mg} / \mathrm{kg})$ also reduced the blood glucose level significantly $(P<0.05)$. On day 28, when compared to diabetic control again, PAFE2-2 $(30 \mathrm{mg} / \mathrm{kg})$ reduced the blood glucose level significantly $(P<$ 0.01). PAFE2-1 $(15 \mathrm{mg} / \mathrm{kg})$ also reduced the blood glucose level significantly $(P<0.05)$ (Table 2$)$.

Body weight of the diabetic control animals reduced markedly compared to that of normal animals; PAFE2 $(30 \mathrm{mg} / \mathrm{kg})$ showed remarkable increase in body weight compared to diabetic control animals (Table 3 ). The levels of Glycosylated Hemoglobin $\left(\mathrm{HbAl}_{\mathrm{C}}\right)$ of diabetic control animals were increased significantly $(P<0.0001)$ compared to that of normal animals; PAFE2-2 $(30 \mathrm{mg} / \mathrm{kg})$ decreased the level of $\mathrm{HbAl}_{\mathrm{C}}$ significantly $(P<0.001)$ compared to diabetic control (Table 3).

3.5. Effect of P. acerifolium on Levels of Serum Liver Enzymes and Lipid Parameters. Interpretation on the levels of ALT, AST, and ALP were found to be significantly increased in diabetic control animals $(P<0.0001)$ compared to that of normal animals. Diabetic animals treated with PAFE2$2(30 \mathrm{mg} / \mathrm{kg})$ showed the significant $(P<0.01)$ reduction on levels of ALT and AST when compared to the diabetic control animals and the identical one showed the significant reduction $(P<0.05)$ on level of ALP when compared to the diabetic control animals (Table 4$)$.

Levels of triglycerides and total cholesterol of diabetic control rats were increased significantly $(P<0.0001)$ compared to that of normal vehicle treated animals and the level of HDL-C $(P<0.0001)$ on the same animals was decreased significantly compared to that of normal vehicle treated animals. Treatment with PAFE2-2 $(30 \mathrm{mg} / \mathrm{kg})$ decreased the level of triglycerides $(P<0.001)$ and total cholesterol $(P<0.01)$ and increased the level of HDLC $(P<0.001)$ significantly when compared to that of diabetic control. PAFE2-1 (15 mg/kg) decreased the level of triglycerides $(P<0.01)$ and total cholesterol $(P<0.05)$ and increased the level of HDL-C $(P<0.05)$ significantly (Table 5).

3.6. Effect of P. acerifolium on In Vivo Antioxidant Enzymes Status. The level of thiobarbituric acid reactive substances (TBARS) was found to increase significantly $(P<0.0001)$ in diabetic control animals compared to that of normal vehicle treated animals and the levels of antioxidant enzymes such as

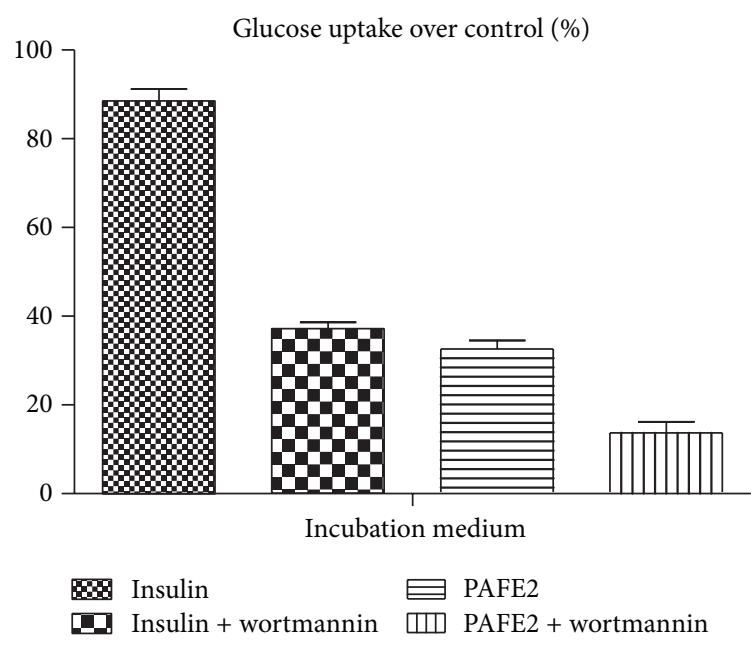

FIGURE 1: Effect of PAFE2 $(1000 \mu \mathrm{g} / \mathrm{mL})$ and insulin $(1 \mathrm{IU} / \mathrm{mL})$ on glucose uptake in L6 muscle cell lines in the absence and presence of wortmannin $(100 \mathrm{nM})$.

catalase, SOD, and GSH were found to decrease significantly $(P<0.0001)$ in diabetic control animals compared to that of normal group. Diabetic animals treated with PAFE2-2 $(30 \mathrm{mg} / \mathrm{kg})$ showed the significant reduction $(P<0.01)$ on levels of TBARS compared to the diabetic control and increased the levels of catalase $(P<0.01)$ and SOD $(P<0.01)$ and reduced GSH $(P<0.01)$ significantly compared to that of diabetic control (Table 6).

3.7. Histopathological Studies. In diabetic control rats, the microscopic section of pancreas showed the features of insulitis and marked evidence of degeneration of $\beta$-cells revealing cellular swelling and cytolysis with pyknotic and fragmented nuclei. As compared to the diabetic control, animals treated with the ethyl acetate fraction and sub fractions of Pterospermum acerifolium did not showed any notable changes in islet cells granulation and cellular arrangements (data not shown).

3.8. Cell Viability and Glucose Uptake Assay. PAFE2 was evaluated for its cytotoxic activity by MTT assay. $\mathrm{CTC}_{50}$ value of PAFE2 were found to be $>1000.00 \mu \mathrm{g} / \mathrm{mL}$. In Glucose uptake assay PAFE2 showed $32.6 \pm 1.93 \%$ glucose uptake over control compared with the standard insulin $(1 \mathrm{IU} / \mathrm{mL})$ which showed $88.5 \pm 2.69 \%$ glucose uptake over control. In the presence of PI3K inhibitor wortmannin, PAFE2 showed $13.7 \pm 2.51 \%$ glucose uptake over control and the standard insulin $(1 \mathrm{IU} / \mathrm{mL})$ showed $37.2 \pm 1.44 \%$ glucose uptake over control (Figure 1).

3.9. HPLC Fingerprint Analysis. The fingerprint analysis of active ethyl acetate subfraction PAFE2 of flowers of Pterospermum acerifolium showed the presence of gallic acid, chlorogenic acid, rutin, quercetin, apigenin, and kaempferol by comparing its retention time and UV spectrum with the reference standards (Table 7; Figure 2). Based on the 
TABLE 1: Effect of ethyl acetate fraction and subfractions of flowers of Pterospermum acerifolium (L.) Willd on changes in blood glucose level during OGTT.

\begin{tabular}{lcccc}
\hline Treatment & & \multicolumn{2}{c}{ Blood glucose level $(\mathrm{mg} / \mathrm{dL})$} & \\
& 0th $\min$ & 30 th $\min$ & 60 th $\min$ & 120 th min \\
\hline Normal control & $75.2 \pm 0.477$ & $144.2 \pm 0.477$ & $139.2 \pm 1.046$ & $121.2 \pm 1.600$ \\
Diabetic control & $353 \pm 11.8^{\text {aaaa }}$ & $442.8 \pm 16.22^{\text {aaaa }}$ & $439.7 \pm 18.97^{\text {aaaa }}$ & $398.2 \pm 12.96^{\text {aaaa }}$ \\
PAFEF1 & $234.6 \pm 5.02$ & $301 \pm 5.373$ & $278.8 \pm 6.582$ & $266.5 \pm 7.602$ \\
PAFEF2 & $233 \pm 16.8$ & $292.2 \pm 16.11$ & $262.7 \pm 15.95$ & $249 \pm 16.48$ \\
PAFE1-1 & $226 \pm 7.44$ & $278.8 \pm 6.258$ & $260.2 \pm 8.845$ & $246.5 \pm 7.610$ \\
PAFE1-2 & $235 \pm 13.5$ & $285.7 \pm 15.82$ & $260.7 \pm 15.68$ & $249.7 \pm 14.71$ \\
PAFE2-1 & $221 \pm 6.11$ & $275 \pm 8.418$ & $253.3 \pm 7.032$ & $236.5 \pm 9.021$ \\
PAFE2-2 & $194 \pm 7.77^{\text {bb }}$ & $247.7 \pm 6.556^{\text {bb }}$ & $221.3 \pm 5.760^{\text {bb }}$ & $200 \pm 7.554^{\text {bb }}$ \\
PAFE3-1 & $269 \pm 11.3^{\text {aa }}$ & $318.5 \pm 15.64^{\text {aa }}$ & $313.3 \pm 12.30^{\text {aaa }}$ & $309.3 \pm 14.18^{\text {aaa }}$ \\
PAFE3-2 & $264 \pm 9.77^{\text {aa }}$ & $314.8 \pm 9.365^{\text {a }}$ & $306 \pm 10.17^{\text {aa }}$ & $295.8 \pm 9.203^{\text {aa }}$ \\
STD drug & $176 \pm 6.90^{\text {bbb }}$ & $225 \pm 4.892^{\text {bbb }}$ & $193 \pm 4.235^{\text {bb }}$ & $177.3 \pm 8.773^{\text {bbb }}$ \\
\hline
\end{tabular}

The results are expressed as mean \pm standard error of the mean (SEM). Probability values of ${ }^{\text {aaaa }} P<0.0001$, ${ }^{\text {aaa }} P<0.001$, ${ }^{\text {aa }} P<0.01$, and ${ }^{\text {a }} P<0.05$ were compared with normal control. Probability values of ${ }^{\mathrm{bbbb}} P<0.0001,{ }^{\mathrm{bbb}} P<0.001,{ }^{\mathrm{bb}} P<0.01$, and ${ }^{\mathrm{b}} P<0.05$ were compared with disease control.

TABLE 2: Effect of ethyl acetate fraction and subfractions of flowers of Pterospermum acerifolium (L.) Willd on changes in blood glucose level.

\begin{tabular}{lcccc}
\hline \multirow{2}{*}{ Treatment } & \multicolumn{3}{c}{ Blood glucose level (mg/dL) } \\
& Day 0 & Day 14 & Day 21 & Day 28 \\
\hline Normal control & $68.83 \pm 1.014$ & $75.33 \pm 0.494$ & $74.50 \pm 0.428$ & $73.83 \pm 1.4$ \\
Diabetic control & $296.5 \pm 9.454$ & $351.2 \pm 11.84^{\text {aaaa }}$ & $360.7 \pm 6.075^{\text {aaaa }}$ & $405.7 \pm 6.344^{\text {aaaa }}$ \\
PAFEF1 & $286.2 \pm 8.975$ & $238.8 \pm 6.983$ & $207.8 \pm 7.674$ & $183.7 \pm 4.240$ \\
PAFEF2 & $302.3 \pm 11.12$ & $234.8 \pm 16.8$ & $205.7 \pm 13.95$ & $176.5 \pm 9.942$ \\
PAFE1-1 & $285.2 \pm 6.858$ & $226.8 \pm 7.726$ & $200.2 \pm 4.658$ & $178.5 \pm 8.655$ \\
PAFE1-2 & $300.7 \pm 10.08$ & $236.5 \pm 13.25$ & $207.3 \pm 11.07$ & $181.8 \pm 8.623$ \\
PAFE2-1 & $282.8 \pm 12.74$ & $225 \pm 8.629$ & $180.5 \pm 5.596^{\text {b }}$ & $151.8 \pm 6.030^{\text {bb }}$ \\
PAFE2-2 & $285 \pm 7.904$ & $193.5 \pm 7.775^{\text {bb }}$ & $152 \pm 6.698^{\text {bbb }}$ & $120.8 \pm 5.375^{\text {bbb }}$ \\
PAFE3-1 & $296.5 \pm 10.30$ & $270.7 \pm 11.41^{\text {aa }}$ & $256.7 \pm 10.74^{\text {aaa }}$ & $248.2 \pm 10.99^{\text {aaa }}$ \\
PAFE3-2 & $279.7 \pm 11.26$ & $265.3 \pm 9.790^{\text {aa }}$ & $239 \pm 12.40^{\text {aa }}$ & $134.5 \pm 4.137^{\text {bbb }}$ \\
STD drug & $290.2 \pm 7.115$ & $178.5 \pm 7.758^{\text {bbb }}$ & $106.5 \pm 3.166^{\text {bbb }}$ \\
\hline
\end{tabular}

The results are expressed as mean \pm standard error of the mean (SEM). Probability values of aaaa $P<0.0001$, ${ }^{\text {aaa }} P<0.001$, ${ }^{\text {aa }} P<0.01$, and ${ }^{\text {a }} P<0.05$ were compared with normal control. Probability values of ${ }^{\mathrm{bbbb}} \mathrm{P}<0.0001$, ${ }^{\mathrm{bbb}} \mathrm{P}<0.001$, ${ }^{\mathrm{bb}} \mathrm{P}<0.01$, and ${ }^{\mathrm{b}} \mathrm{P}<0.05$ were compared with disease control.

TABLE 3: Effect of ethyl acetate fraction and subfractions of flowers of Pterospermum acerifolium (L.) Willd on body weight changes and glycosylated $\mathrm{Hb}$.

\begin{tabular}{lccc}
\hline Treatment & \multicolumn{2}{c}{ Body weight (gms) } & Glycosylated Hb (\%) \\
\hline Normal control & Initial & $241.1 \pm 2.740$ & $2.872 \pm 0.277$ \\
Diabetic control & $197.5 \pm 2.707$ & $149.7 \pm 6.182$ & $7.932 \pm 0.109^{\text {aaaa }}$ \\
PAFEF1 & $200.4 \pm 4.845$ & $205.2 \pm 2.968$ & $5.680 \pm 0.060$ \\
PAFEF2 & $197.9 \pm 5.206$ & $210.7 \pm 6.634$ & $5.412 \pm 0.023^{\mathrm{b}}$ \\
PAFE1-1 & $199.1 \pm 4.202$ & $201.3 \pm 4.148$ & $6.417 \pm 0.067^{\text {aa }}$ \\
PAFE1-2 & $199.9 \pm 3.738$ & $206.3 \pm 3.983$ & $5.892 \pm 0.104$ \\
PAFE2-1 & $193.4 \pm 2.815$ & $201.8 \pm 3.445$ & $4.708 \pm 0.055^{\text {bb }}$ \\
PAFE2-2 & $199.9 \pm 2.854$ & $219.3 \pm 3.157$ & $4.227 \pm 0.075^{\text {bbb }}$ \\
PAFE3-1 & $203.7 \pm 2.749$ & $183.4 \pm 3.410$ & $6.770 \pm 0.278^{\text {aa }}$ \\
PAFE3-2 & $197.3 \pm 2.953$ & $184.4 \pm 4.275$ & $6.690 \pm 0.049^{\text {aaa }}$ \\
STD drug & $203.2 \pm 2.793$ & $231.7 \pm 3.740$ & $3.337 \pm 0.097^{\text {bbbb }}$ \\
\hline
\end{tabular}

The results are expressed as mean \pm standard error of the mean (SEM). Probability values of ${ }^{\text {aaaa }} P<0.0001$, ${ }^{\text {aaa }} P<0.001$, ${ }^{\text {aa }} P<0.01$, and ${ }^{\text {a } P}<0.05$ were compared with normal control. Probability values of ${ }^{\mathrm{bbbb}} P<0.0001,{ }^{\mathrm{bbb}} P<0.001$, ${ }^{\mathrm{bb}} P<0.01$, and ${ }^{\mathrm{b}} \mathrm{P}<0.05$ were compared with disease control. 
TABLE 4: Effect of ethyl acetate fraction and subfractions of flowers of Pterospermum acerifolium (L.) Willd on levels of serum liver enzymes.

\begin{tabular}{lccc}
\hline Treatment & ALT (IU/L) & AST (IU/L) & ALP (IU/L) \\
\hline Normal control & $25.48 \pm 0.337$ & $32.14 \pm 0.24$ & $11.88 \pm 0.24$ \\
Diabetic control & $54.91 \pm 0.45^{\text {aaa }}$ & $72.35 \pm 0.365^{\text {aaaa }}$ & $27.16 \pm 0.041^{\text {aaa }}$ \\
PAFEF1 & $44.07 \pm 0.273$ & $58.28 \pm 0.348$ & $22.39 \pm 0.085$ \\
PAFEF2 & $41.60 \pm 0.444$ & $56.25 \pm 0.387$ & $21.33 \pm 0.069$ \\
PAFE1-1 & $42.03 \pm 0.711$ & $53.48 \pm 0.570$ & $20.27 \pm 0.064$ \\
PAFE1-2 & $40.94 \pm 0.195$ & $51.34 \pm 0.364^{\mathrm{b}}$ & $18.25 \pm 0.054$ \\
PAFE2-1 & $38.75 \pm 0.359^{\text {bb }}$ & $43.86 \pm 0.770^{\text {bb }}$ & $17.21 \pm 0.039$ \\
PAFE2-2 & $31.45 \pm 0.371^{\text {bbb }}$ & $41.73 \pm 0.484^{\text {bbb }}$ & $15.21 \pm 0.053^{\text {b }}$ \\
PAFE3-1 & $51.64 \pm 0.478^{\text {aaaa }}$ & $69.76 \pm 0.208^{\text {aaaa }}$ & $28.37 \pm 0.073^{\text {aaaa }}$ \\
PAFE3-2 & $49.77 \pm 0.201^{\text {aaa }}$ & $68.90 \pm 0.612^{\text {aaa }}$ & $27.32 \pm 0.033^{\text {aaa }}$ \\
STD drug & $28.78 \pm 0.251^{\text {bbbb }}$ & $37.17 \pm 0.306^{\text {bbbb }}$ & $14.50 \pm 0.064^{\text {bb }}$ \\
\hline
\end{tabular}

The results are expressed as mean \pm standard error of the mean (SEM). Probability values of ${ }^{\text {aaaa }} P<0.0001$, ${ }^{\text {aaa }} P<0.001$, ${ }^{\text {aa }} P<0.01$, and ${ }^{\text {a }} P<0.05$ were compared with normal control. Probability values of ${ }^{\mathrm{bbbb}} P<0.0001,{ }^{\mathrm{bbb}} P<0.001$, ${ }^{\mathrm{b}} \mathrm{P}<0.01$, and ${ }^{\mathrm{b}} \mathrm{P}<0.05$ were compared with disease control.

TABLE 5: Effect of ethyl acetate fraction and subfractions of flowers of Pterospermum acerifolium (L.) Willd on levels of lipid parameter.

\begin{tabular}{lccc}
\hline Treatment & Triglycerides $(\mathrm{mg} / \mathrm{dL})$ & Total cholesterol $(\mathrm{mg} / \mathrm{dL})$ & HDL-C $(\mathrm{mg} / \mathrm{dL})$ \\
\hline Normal control & $91.66 \pm 0.495$ & $57.53 \pm 0.311$ & $57.39 \pm 0.407$ \\
Diabetic control & $214.3 \pm 1.261^{\text {aaaa }}$ & $159.2 \pm 1.221^{\text {aaaa }}$ & $17.59 \pm 0.514^{\text {aaaa }}$ \\
PAFEF1 & $139 \pm 1.289$ & $105.2 \pm 0.701$ & $34.51 \pm 0.671$ \\
PAFEF2 & $130.2 \pm 1.488$ & $97.90 \pm 0.628$ & $37.66 \pm 0.458$ \\
PAFE1-1 & $125.2 \pm 0.668$ & $99.17 \pm 0.708$ & $38.53 \pm 0.390$ \\
PAFE1-2 & $122 \pm 0.917^{\text {bb }}$ & $94.43 \pm 1.144$ & $43.78 \pm 1.178^{\text {b }}$ \\
PAFE2-1 & $104 \pm 1.234^{\text {bbb }}$ & $70.12 \pm 0.812^{\text {bb }}$ & $50.69 \pm 0.466^{\text {bb }}$ \\
PAFE2-2 & $94.86 \pm 1.075^{\text {bbbb }}$ & $66.36 \pm 0.71^{\text {bbb }}$ & $54.41 \pm 0.413^{\text {bbb }}$ \\
PAFE3-1 & $184.8 \pm 1.188^{\text {aaaa }}$ & $144 \pm 0.648^{\text {aaaa }}$ & $21.60 \pm 0.305^{\text {aaaa }}$ \\
PAFE3-2 & $188 \pm 0.816^{\text {aaa }}$ & $140 \pm 0.546^{\text {aaa }}$ & $24.53 \pm 0.501^{\text {aaa }}$ \\
STD drug & $125.8 \pm 1.079$ & $65.04 \pm 0.731^{\text {bbb }}$ & $52.47 \pm 0.315$ \\
\hline
\end{tabular}

The results are expressed as mean \pm standard error of the mean (SEM). Probability values of ${ }^{\text {aaaa }} P<0.0001$, ${ }^{\text {aaa }} P<0.001$, ${ }^{\text {aa }} P<0.01$, and ${ }^{\text {a }} P<0.05$ were compared with normal control. Probability values of ${ }^{\mathrm{bbbb}} P<0.0001,{ }^{\mathrm{bbb}} P<0.001,{ }^{\mathrm{bb}} P<0.01$, and ${ }^{\mathrm{b}} P<0.05$ were compared with disease control.

peak area, quercetin and apigenin were found as the major constituents in PAFE2.

3.10. Molecular Modelling Studies. To investigate the interaction of quercetin and apigenin, molecular docking simulations of the binding of those molecules with glycogen phosphorylase active site were carried out using Autodock 4.2. From this study we found that quercetin is making eight $\mathrm{H}$-bond interactions with the active site residues Asn 284, Lys 568, Lys 574, Tyr 648, Gly 675, Asn 484, and Val 567 and $\pi$ electrons of flavone nucleus of quercetin is making $\pi-\pi$ stacking interaction with Tyr 648 (Figure 3(a)). The estimated free energy binding of quercetin was found to be $-8.27 \mathrm{kcal} \mathrm{mol}^{-1}$ with estimated inhibition constant $\left(K_{i}\right)$ of $0.87 \mu \mathrm{M}$. Similarly, apigenin is making three hydrogen bond interactions with the active site residues Glu 88, His 377, and Asn 484 (Figure 3(b)). The estimated free energy binding of apigenin was found to be $-8.08 \mathrm{kcal} \mathrm{mol}^{-1}$ with estimated inhibition constant $\left(K_{i}\right)$ of $1.2 \mu \mathrm{M}$, which infers clearly that the major constituents of bioactive subfraction can inhibit glycogen phosphorylase enzyme.

\section{Discussion}

Diabetes mellitus is regarded as a noncurable but controllable disease. Progressive nature of the disease necessitates constant reassessment of glycaemic control in people with diabetes and appropriate adjustment of therapeutic regimens [19]. $\alpha$-amylase catalyzes the hydrolysis of $\alpha$-1,4-glucosidic linkages of starch, glycogen, and various oligosaccharides and simplifies the availability of sugars for the intestinal absorption. Inhibition of this enzyme activity in the digestive tract of humans is considered to be effective to control diabetes by diminishing the absorption of glucose decomposed from starch by this enzyme $[20,21]$. In the present study, ethyl acetate fraction PAFEF was found as the potential $\alpha$-amylase inhibitor amongst the tested extract and fractions. Hence PAFEF was selected for further subfractionation and in vivo studies. 
TABLE 6: Effect of ethyl acetate fraction and subfractions of flowers of Pterospermum acerifolium (L.) Willd on levels of oxidative stress marker (TBARs) and antioxidant enzymes (Catalase, Glutathione, and SOD).

\begin{tabular}{|c|c|c|c|c|}
\hline Treatment & TBARS & Catalase & Glutathione & SOD \\
\hline Normal control & $0.98 \pm 0.16$ & $74.82 \pm 3.67$ & $48.72 \pm 2.21$ & $7.86 \pm 1.09$ \\
\hline Diabetic control & $1.74 \pm 0.81^{\text {aaaa }}$ & $30.78 \pm 3.16^{\text {aаaа }}$ & $23.46 \pm 2.60^{\text {aаaа }}$ & $3.7 \pm 0.34^{\text {aаaа }}$ \\
\hline PAFEF1 & $1.43 \pm 0.62^{\mathrm{a}}$ & $55.71 \pm 3.22$ & $36.86 \pm 1.23^{\mathrm{a}}$ & $4.50 \pm 0.18^{\mathrm{a}}$ \\
\hline PAFEF2 & $1.38 \pm 0.86$ & $57.82 \pm 1.16$ & $39.33 \pm 2.71$ & $4.88 \pm 0.61$ \\
\hline PAFE1-1 & $1.36 \pm 0.16$ & $54.17 \pm 3.17$ & $37.41 \pm 1.81$ & $5.19 \pm 0.11$ \\
\hline PAFE1-2 & $1.31 \pm 0.32$ & $59.23 \pm 1.72$ & $39.41 \pm 2.86$ & $5.43 \pm 0.19$ \\
\hline PAFE2-1 & $1.15 \pm 0.16^{\mathrm{b}}$ & $62.81 \pm 1.81^{\mathrm{b}}$ & $41.96 \pm 1.33^{\mathrm{bb}}$ & $6.10 \pm 0.22^{b}$ \\
\hline PAFE2-2 & $1.10 \pm 0.21^{\mathrm{bb}}$ & $65.88 \pm 1.26^{\mathrm{bb}}$ & $43.83 \pm 1.81^{\mathrm{bb}}$ & $6.35 \pm 0.13^{\mathrm{bb}}$ \\
\hline PAFE3-1 & $1.71 \pm 0.10^{\text {aаaа }}$ & $29.16 \pm 2.33^{\text {aaa }}$ & $26.16 \pm 1.33^{\text {aaa }}$ & $3.71 \pm 0.31^{\text {aaa }}$ \\
\hline PAFE3-2 & $1.67 \pm 0.23^{\text {aaa }}$ & $34.62 \pm 1.70^{\mathrm{aa}}$ & $28.33 \pm 1.96^{\text {aaa }}$ & $3.96 \pm 0.33^{\text {aaa }}$ \\
\hline STD drug & $1.03 \pm 0.50^{\mathrm{bb}}$ & $68.92 \pm 1.86^{\mathrm{bbb}}$ & $44.67 \pm 2.16^{\mathrm{bbb}}$ & $6.41 \pm 0.16^{\mathrm{bbb}}$ \\
\hline
\end{tabular}

Thiobarbituricacid reactive substances (TBARS) expressed as $\mathrm{nM}$ of MDA/mg protein; Catalase expressed as nmoles of $\mathrm{H}_{2} \mathrm{O}_{2}$ consumed/min/mg protein; Superoxide dismutase (SOD) expressed as $\mathrm{U} / \mathrm{mg}$ protein; Glutathione expressed as $\mu \mathrm{g}$ of $\mathrm{GSH} / \mathrm{mg}$ protein. The results are expressed as mean \pm standard error of the mean (SEM). Probability values of aaaa $P<0.0001$, ${ }^{\text {aaa }} P<0.001$, ${ }^{\text {aa }} P<0.01$, and ${ }^{\text {a }} P<0.05$ were compared with normal control. Probability values of ${ }^{\text {bbbb }} P<0.0001,{ }^{\text {bbb }} P<0.001,{ }^{\text {bb }} P<0.01$, and ${ }^{\mathrm{b}} P<0.05$ were compared with disease control.

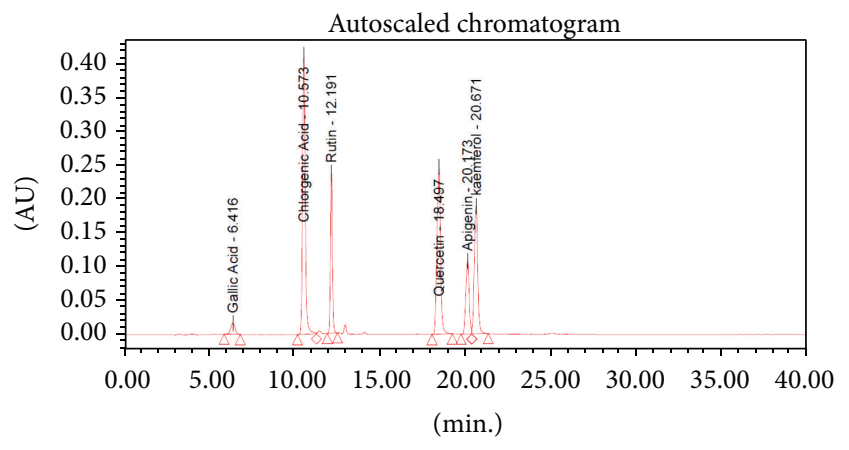

(a)

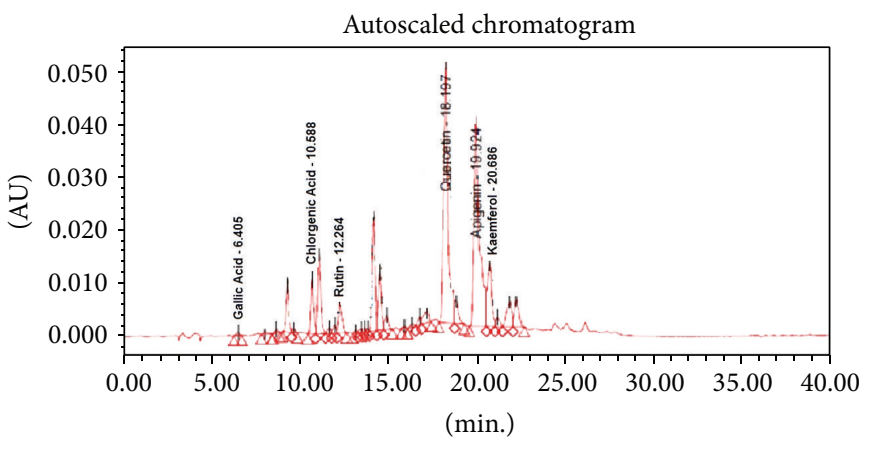

(b)

FIGURE 2: (a) HPLC chromatogram of reference standards (b) HPLC chromatogram of subfraction PAFE2.

TABLE 7: HPLC chromatogram profile of standard reference compounds and fingerprint of PAFE2.

\begin{tabular}{lccc}
\hline \multirow{2}{*}{ S. Number } & Reference compounds & \multicolumn{2}{c}{ Retention time (Rt) } \\
& & 6.416 & 6.405 \\
\hline 1 & Gallic acid & 10.573 & 10.588 \\
2 & Chlorogenic acid & 12.191 & 12.204 \\
3 & Rutin & 18.497 & 18.197 \\
4 & Quercetin & 20.173 & 19.924 \\
5 & Apigenin & 20.671 & 20.686 \\
6
\end{tabular}

Diabetic patients however cannot control their postprandial blood glucose efficiently due to the insufficient insulin secretion or response, which results in postprandial hyperglycemia and it is an important contributing factor for diabetic complications [22]. PAFE2 (30 mg/kg) treated diabetic rats significantly reduces the blood glucose levels at 60 th and 120th min when compared to that of diabetic control and it implies the further scope of the drug to be studied in detail on diabetic complications using animal models.

The diabetic syndrome in rats administered STZ and partially protected with suitable dosages of nicotinamide is characterized by stable moderate hyperglycemia [23]. In the present study STZ-nicotinamide induced diabetic rats treated with PAFE2 $(30 \mathrm{mg} / \mathrm{kg})$ reduces the blood glucose level at 14 th, 21st, and 28th days significantly and it showed clearly its antihyperglycemic effect. In diabetes, there is an increased glycosylation of a number of proteins therefore measurement of $\mathrm{HbAl}_{\mathrm{C}}$ has proven to be particularly useful in monitoring the effectiveness of therapy [3]. Diabetic animals treated with PAFE2 $(15 \mathrm{mg} / \mathrm{kg} \& 30 \mathrm{mg} / \mathrm{kg})$ reduced the $\mathrm{HbAl}_{\mathrm{C}}$ levels significantly compared to that of diabetic control group and it could also be due to its antihyperglycemic property.

The level of activities of liver biomarker enzymes such as ALT, AST, and ALP were used in the evaluation of hepatic disorders and increase in the serum levels of these enzymes in diabetic rats that substantiated the hepatic damage [11]. The observed significant reduction in the serum level of these enzymes in PAFE2 $(30 \mathrm{mg} / \mathrm{kg}$ and $15 \mathrm{mg} / \mathrm{kg})$ treated diabetic 


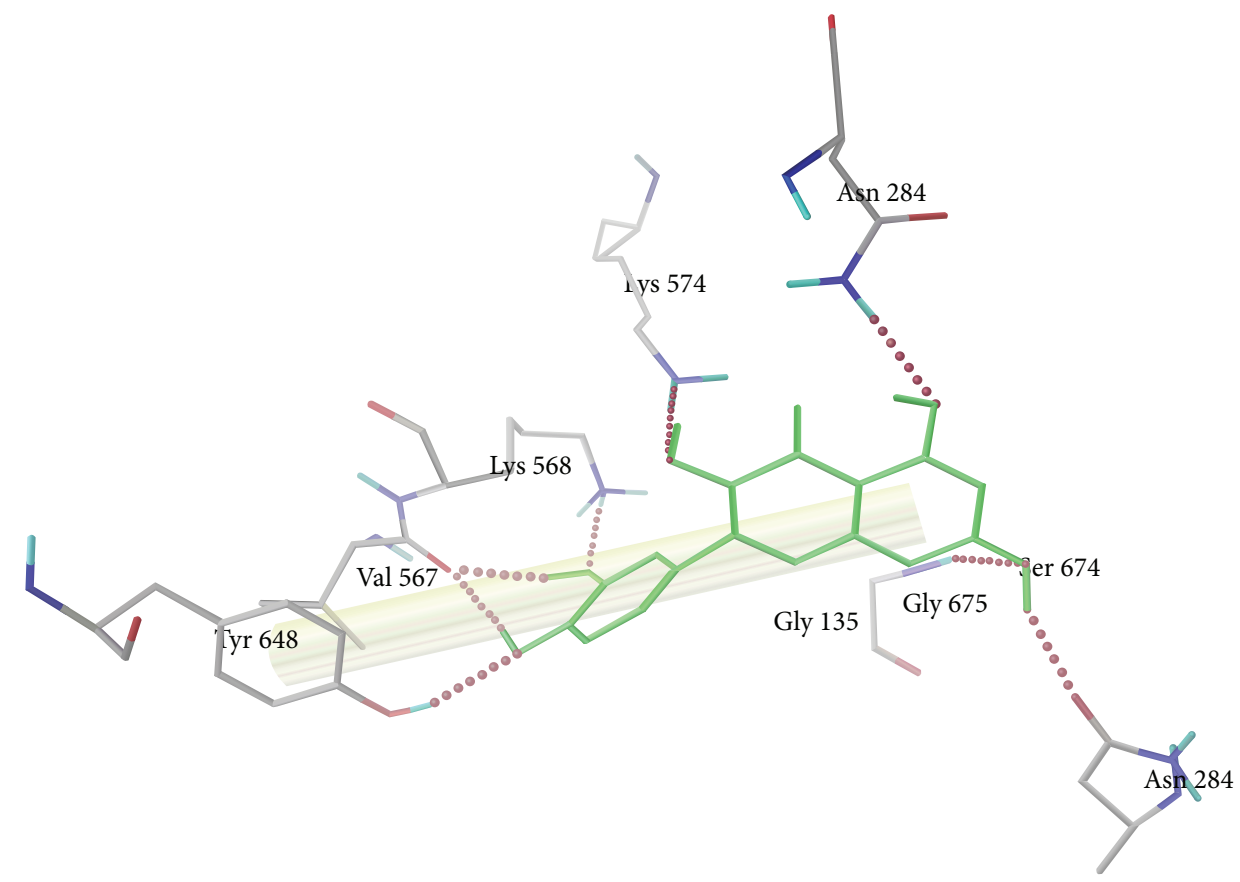

(a)

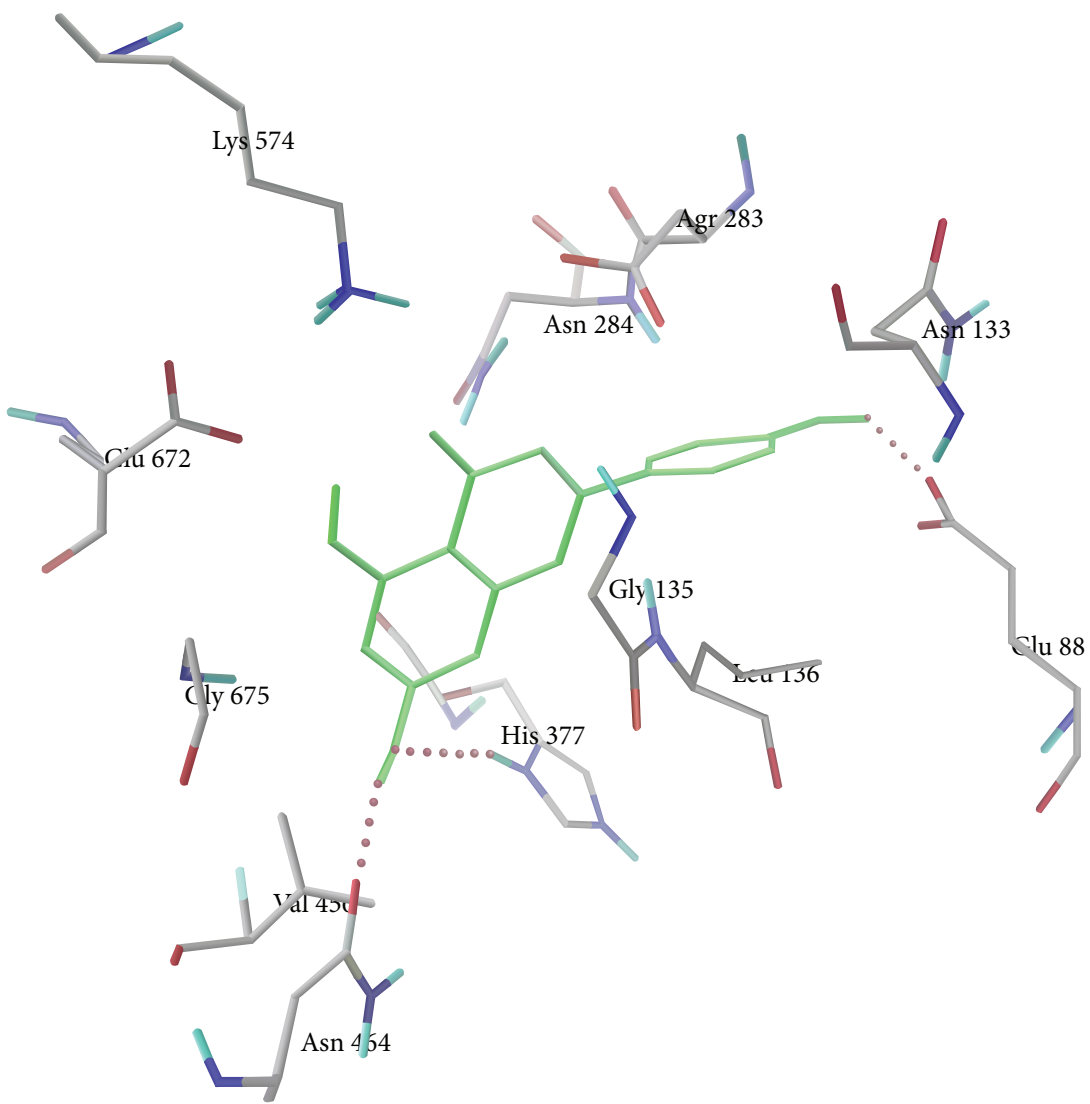

(b)

FIGURE 3: Hydrogen bond interactions between amino acid residues in the active site pocket of glycogen phosphorylase and (a) quercetin and (b) apigenin. 
animals indicates its hepatoprotective role in preventing diabetic complications. The elevation of serum triglycerides, total cholesterol, and the decline in the level of HDL-C was well documented in diabetic animals. In PAFE2 $(30 \mathrm{mg} / \mathrm{kg}$ and $15 \mathrm{mg} / \mathrm{kg}$ ) treated diabetic animals showed significant reduction in the level of triglycerides, total cholesterol, and raise in the level of HDL-C and it clearly showed its effect on lipid regulation systems.

In diabetic control animals it was found clearly that there was a marked increase in the levels of TBARS and decrease in the levels of antioxidant enzymes such as catalase, GSH, and SOD $[24,25]$. Treatment with PAFE2 $(30 \mathrm{mg} / \mathrm{kg}$ \& $15 \mathrm{mg} / \mathrm{kg}$ ) reduces the TBARS levels and increases the levels of antioxidant enzymes compared to that of diabetic control and it clearly implies its role against oxidative stress.

Histopathological studies showed that there was no regeneration of islet cells or no insulinogenic property and it reveals that the PAFE2 site of action may be extrapancreatic and not the regeneration of $\beta$-cells and the decrease in blood glucose may be attributed to the stimulation of glucose uptake by peripheral tissues and decrease in the gluconeogenesis. There are marked numbers of medicinal plants reported for antidiabetic activity without the stimulation of insulin secretion [23].

L6 myotubes is a well-established skeletal muscle model for studying glucose uptake process and it is one of the key insulin targeted tissues in maintaining whole body glucose homeostasis, through the stimulation of glucose uptake mediated by GLUT4 translocation [26]. The results obtained demonstrated that PAFE2 enhances the basal glucose uptake and it is clear that mimic insulin action. Many reports emphasize that PI3K plays a major role in insulin signaling pathway and regulates insulin-mediated glucose transport [27]. Pretreatment with specific PI3K inhibitor (wortmannin) resulted in a decline in the glucose uptake activity of PAFE2, suggesting that glucose transport is dependent primarily on the involvement of PI3K. Hence PAFE2 decreases blood glucose level by increasing the glucose uptake in peripheral tissues through PI3K mediated Glut4 translocation. The HPLC fingerprint analysis reveals the presence of quercetin and apigenin as the major constituents. As quercetin and apigenin are the major components from the active subfraction PAFE2, they play a major role in establishing the mechanism of action for its antidiabetic activity. In the literature, it has been reported earlier that these compounds are well-known antidiabetic compounds in particular for its insulin mimetic property by increasing the glucose uptake in peripheral tissues [28]. The inhibition of hepatic glycogen phosphorylase could suppress glucose production arising from both glycogenolysis and gluconeogenesis [29]. Molecular modelling studies clearly revealed the inhibition potential of the identified major constituents quercetin and apigenin of PAFE2 by its lowest binding energy and estimated inhibition constant $\left(K_{i}\right)$ values. Hence the above results evidenced strongly that the probable glucose lowering mechanism of action of active subfraction PAFE2 is by increasing the glucose uptake in peripheral tissues and by inhibition of gluconeogenesis. Establishment of mechanism of action for antidiabetic property and identification of bioactive molecules responsible for the glucose lowering effect were undertaken for the first time with flowers of Pterospermum acerifolium.

\section{Conflict of Interests}

The authors report no conflict of interests. The authors alone are responsible for the content and writing of the paper.

\section{Acknowledgments}

The authors would like to acknowledge Department of Pharmaceutical Sciences Birla Institute of Technology, Mesra, Ranchi, India for providing the necessary facilities to carry out the study and University Grants Commission (UGC) for providing financial assistance under the scheme of major research project (MRP), New Delhi, India. (Grant no. F.39157/2010 (SR)). The authors are thankful to Dr. K. K. Singh, Chairman, Veterinary pathology division, Birsa agricultural university, Ranchi for assistance in histopathology observations. The authors would like to acknowledge the assistance offered by Radiant research services, Bangalore, in cell line assays.

\section{References}

[1] S. Bastaki, "Diabetes mellitus and its treatment," International Journal of Diabetes and Metabolism, vol. 13, no. 3, pp. 111-134, 1995.

[2] P. M. Mazumder, P. Rathinavelusamy, and D. Sasmal, "Role of antioxidants in phytomedicine with special reference to antidiabetic herbs," Asian Pacific Journal of Tropical Disease, vol. 2, pp. S969-S979, 2012.

[3] D. E. Goldstein, "How much do you know about glycated hemoglobin testing?" Clinical Diabetes, vol. 13, no. 4, pp. 60-63, 1955.

[4] E. A. Nyenwe, T. W. Jerkins, G. E. Umpierrez, and A. E. Kitabchi, "Management of type 2 diabetes: evolving strategies for the treatment of patients with type 2 diabetes," Metabolism: Clinical and Experimental, vol. 60, no. 1, pp. 1-23, 2011.

[5] P. K. Mukherjee, K. Maiti, K. Mukherjee, and P. J. Houghton, "Leads from Indian medicinal plants with hypoglycemic potentials," Journal of Ethnopharmacology, vol. 106, no. 1, pp. 1-28, 2006.

[6] K. R. Kirtikar and B. D. Basu, "Indian medical plants," Journal of Pharmacy Research, vol. 2, pp. 785-788, 1935.

[7] R. N. Chopra, S. L. Nayar, and I. C. Chopra, Glossary of Indian Medicinal Plants, Council of Scientific \& Industrial Research, New Delhi, India, 1956.

[8] P. Dixit, M. P. Khan, G. Swarnkar, N. Chattopadhyay, and R. Maurya, "Osteogenic constituents from Pterospermum acerifolium Willd. flowers," Bioorganic \& Medicinal Chemistry Letters, vol. 21, no. 15, pp. 4617-4621, 2011.

[9] H. Ali, P. J. Houghton, and A. Soumyanath, " $\alpha$-Amylase inhibitory activity of some Malaysian plants used to treat diabetes; with particular reference to Phyllanthus amarus," Journal of Ethnopharmacology, vol. 107, no. 3, pp. 449-455, 2006.

[10] P. Masiello, C. Broca, R. Gross et al., "Experimental NIDDM: development of a new model in adult rats administered streptozotocin and nicotinamide," Diabetes, vol. 47, no. 2, pp. 224-229, 1998. 
[11] G. R. Gandhi, S. Ignacimuthu, and M. G. Paulraj, "Hypoglycemic and $\beta$-cells regenerative effects of Aegle marmelos (L.) Corr. bark extract in streptozotocin-induced diabetic rats," Food and Chemical Toxicology, vol. 50, no. 5, pp. 1667-1674, 2012.

[12] T. F. Slater and B. C. Sawyer, "The stimulatory effects of carbon tetrachloride and other halogenoalkanes on peroxidative reactions in rat liver fractions in vitro," Biochemical Journal, vol. 123, no. 5, pp. 805-814, 1971.

[13] H. Aebi, "[13] Catalase in vitro," Methods in Enzymology, vol. 105, pp. 121-126, 1984.

[14] H. P. Misra and I. Fridovich, "The role of superoxide anion in the autoxidation of epinephrine and a simple assay for superoxide dismutase," The Journal of Biological Chemistry, vol. 247, no. 10, pp. 3170-3175, 1972.

[15] M. S. Moron, J. W. Depierre, and B. Mannervik, "Levels of glutathione, glutathione reductase and glutathione $S$-transferase activities in rat lung and liver," Biochimica et Biophysica Acta, vol. 582, no. 1, pp. 67-78, 1979.

[16] F. Denizot and R. Lang, "Rapid colorimetric assay for cell growth and survival: modifications to the tetrazolium dye procedure giving improved sensitivity and reliability," Journal of Immunological Methods, vol. 89, no. 2, pp. 271-277, 1986.

[17] A. Yap, S. Nishiumi, K.-I. Yoshida, and H. Ashida, "Rat L6 myotubes as an in vitro model system to study GLUT4dependent glucose uptake stimulated by inositol derivatives," Cytotechnology, vol. 55, no. 2-3, pp. 103-108, 2007.

[18] Z. Cheng, T. Pang, M. Gu et al., "Berberine-stimulated glucose uptake in L6 myotubes involves both AMPK and p38 MAPK," Biochimica et Biophysica Acta, vol. 1760, no. 11, pp. 1682-1689, 2006.

[19] M. S. Deutschländer, M. van de Venter, S. Roux, J. Louw, and N. Lall, "Hypoglycaemic activity of four plant extracts traditionally used in South Africa for diabetes," Journal of Ethnopharmacology, vol. 124, no. 3, pp. 619-624, 2009.

[20] Y. A. Lee, J. C. Eun, T. Tanaka, and T. Yokozawa, "Inhibitory activities of proanthocyanidins from persimmon against oxidative stress and digestive enzymes related to diabetes," Journal of Nutritional Science and Vitaminology, vol. 53, no. 3, pp. 287-292, 2007.

[21] Y. Hara and M. Honda, "The inhibition of a-amylase by tea polypphenols," Agricultural and Biological Chemistry, vol. 54, pp. 1939-1945, 1990.

[22] C. Wu, Y. Li, Y. Chen et al., "Hypoglycemic effect of Belamcanda chinensis leaf extract in normal and STZ-induced diabetic rats and its potential active faction," Phytomedicine, vol. 18, no. 4, pp. 292-297, 2011.

[23] A. Shirwaikar, K. Rajendran, and I. S. R. Punitha, "Antidiabetic activity of alcoholic stem extract of Coscinium fenestratum in streptozotocin-nicotinamide induced type 2 diabetic rats," Journal of Ethnopharmacology, vol. 97, no. 2, pp. 369-374, 2005.

[24] S. Srinivasan and L. Pari, "Ameliorative effect of diosmin, a citrus flavonoid against streptozotocin-nicotinamide generated oxidative stress induced diabetic rats," Chemico-Biological Interactions, vol. 195, no. 1, pp. 43-51, 2012.

[25] M. Vijayakumar, R. Govindarajan, G. M. M. Rao et al., "Action of Hygrophila auriculata against streptozotocin-induced oxidative stress," Journal of Ethnopharmacology, vol. 104, no. 3, pp. 356-361, 2006.

[26] S. Sujatha, S. Anand, K. N. Sangeetha et al., "Biological evaluation of ( $3 \beta)$-STIGMAST-5-EN-3-OL as potent anti-diabetic agent in regulating glucose transport using in vitro model,"
International Journal of Diabetes Mellitus, vol. 2, no. 2, pp. 101109, 2010.

[27] A. Khan and J. Pessin, "Insulin regulation of glucose uptake: a complex interplay of intracellular signalling pathways," Diabetologia, vol. 45, no. 11, pp. 1475-1483, 2002.

[28] K. Hanhineva, R. Törrönen, I. Bondia-Pons et al., "Impact of dietary polyphenols on carbohydrate metabolism," International Journal of Molecular Sciences, vol. 11, no. 4, pp. 1365-1402, 2010.

[29] L. Somsák, K. Czifrák, M. Tóth et al., "New inhibitors of glycogen phosphorylase as potential antidiabetic agents," Current Medicinal Chemistry, vol. 15, no. 28, pp. 2933-2983, 2008. 

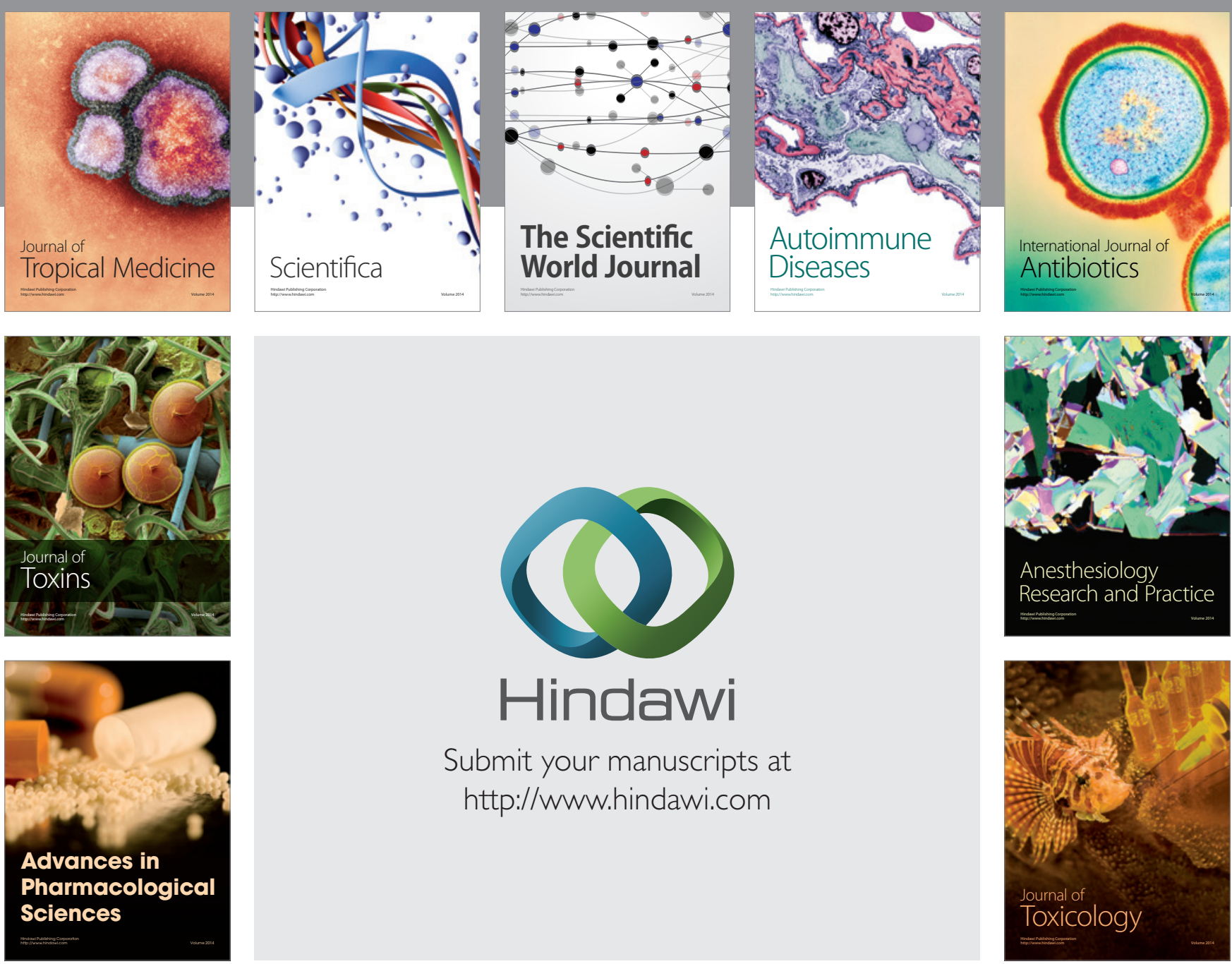

\section{Hindawi}

Submit your manuscripts at

http://www.hindawi.com
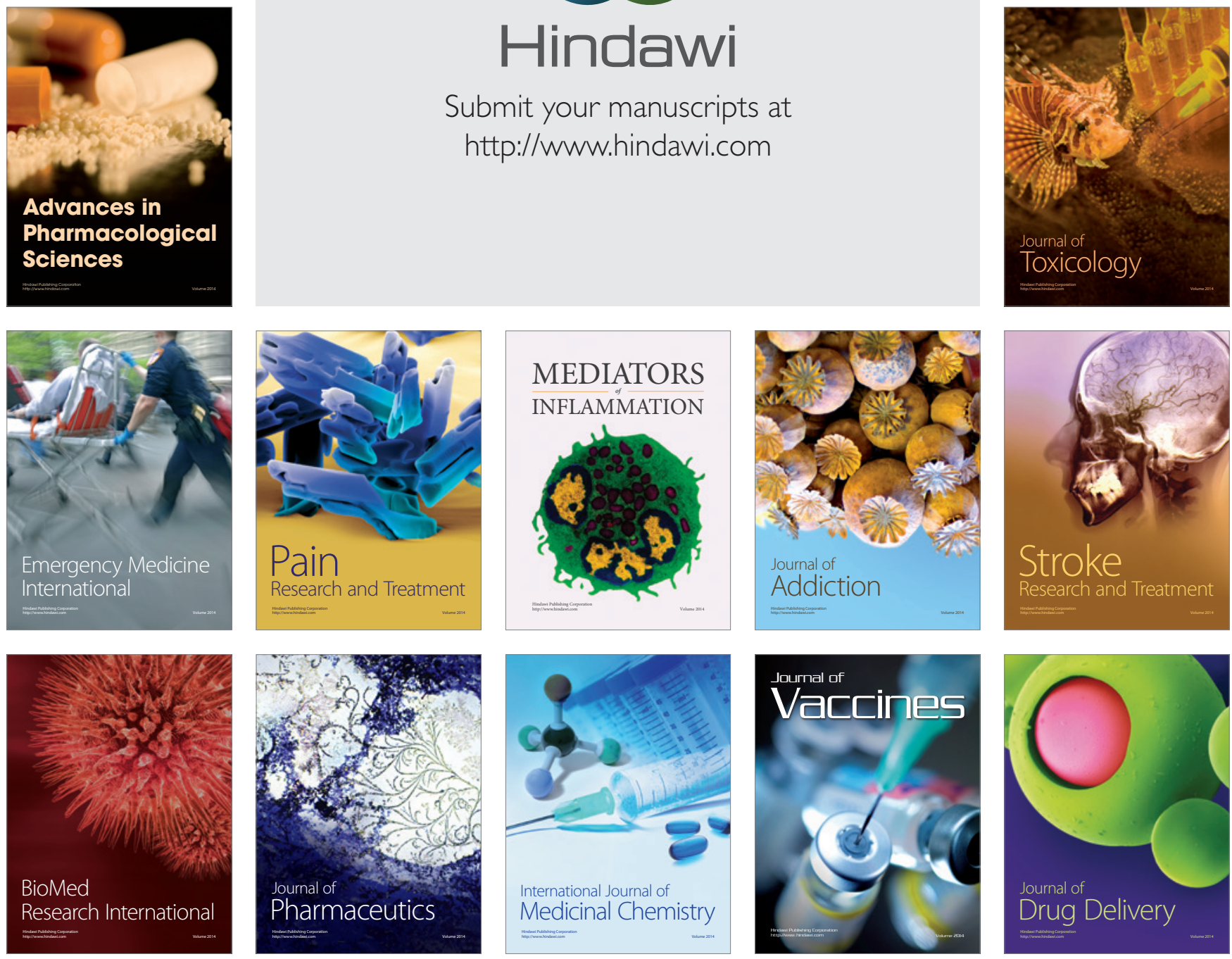